\title{
DESIGN AND ANALYSIS OF T-STUB U-SLOT NOTCH BAND FREQUENCY RECONFIGURABLE ANTENNA USING PARAMETRIC ANALYSIS FOR WIRELESS COMMUNICATION APPLICATIONS
}

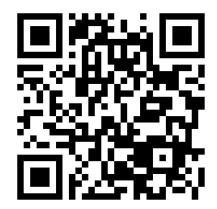

\author{
B. Siva Prasad $1{ }^{凶}$, P. Mallikarjuna Rao ${ }^{2}$ \\ ${ }^{1}$ Research Scholar, ECE Department, AUCE (A), Andhra University, Visakhapatnam, AP, India \\ 2 Professor, ECE Department, AUCE (A), Andhra University, Visakhapatnam, AP, India
}

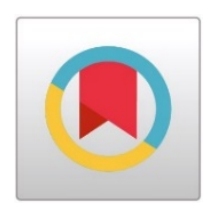

DOI: https://doi.org/10.29121/ijetmr.v7.i7.2020.714

Article Citation: B. Siva Prasad, and P. Mallikarjuna Rao. (2020). DESIGN AND ANALYSIS OF T-STUB U-SLOT NOTCH BAND FREQUENCY RECONFIGURABLE ANTENNA USING PARAMETRIC ANALYSIS FOR WIRELESS COMMUNICATION APPLICATIONS. International Journal of Engineering Technologies and Management Research, 7(7), 15-20.

https://doi.org/10.29121/ijetmr.v7 .i7.2020.714

Published Date: 13 July 2020

Keywords:

Reconfigurability

Bandwidth

Notch Band

PIN Diodes

\section{ABSTRACT}

The design and analysis of a T-Stub U-Slot Frequency Reconfigurable Notch band antenna is considered in the present work using Coplanar Waveguide feed network for an efficient power transfer to improve the bandwidth characteristics of the antenna. The designed antenna has a dimension of 24X21X1.6 mm with FR4 substrate having a permittivity of 4.4. The proposed antenna consists of a T-Stub and U-Slots which are used to enhance the performance characteristics of the antenna. The reconfigurability is achieved by placing PIN diodes at T-Stub and U-Slots of the antenna design. The designed antenna is more suitable for WLAN, Wi$\mathrm{Fi}$, LTE and Bluetooth applications. Simulation results are obtained using CST tool and the same are presented at the end.

\section{INTRODUCTION}

Generally, a single antenna provides limited resonant frequencies, single band of operation with limited gain in the present scenario. In order to overcome the single band frequency of operation and limited gain, frequency diversity with multi resonant characteristics from single antenna is essential for the above said applications. In view of this, in the present work, T-Stub U-Slot frequency reconfigurable antenna is designed and its parametric analysis is evaluated. Researchers designed various multiple band antennas to addresses different wireless communication applications such as GPS, GSM, PCS, UMTS, Bluetooth, LTE, Wi-Fi and WLAN etc [1], [2], [3], [4], [5], [6].

Usage of greater number of wireless platforms will have frequency bands and diversity problems. In this paper, three PIN diodes are used to attain frequency reconfigurability. PIN diodes are utilised for high power handling capability, very less driving voltage and low cost. The parametric analysis of T-Stub U-Slot notch band [7] frequency reconfigurable antenna is carried out by varying three important parameters namely, width of the feed ( $\left.\mathrm{W}_{\mathrm{f}}\right)$, width of the T-stub (T3) and length of the U-slot (S1) and the results are presented at the end.

(C) 2020 The Author(s). This is an open access article distributed under the terms of the Creative Commons Attribution License, which permits unrestricted use, distribution, and reproduction in any medium, provided the original author and source are credited. 


\section{ANTENNA DESIGN}

The antenna is constructed on FR4 substrate material with permittivity 4.4 and loss tangent 0.02 . the dimensions of the antenna are calculated based on the dielectric constant of the substrate material, resonant frequency and impedance with respect to $50 \mathrm{ohms}$. The design related mathematical formulation is presented in this section with list of parameters. In the patch antenna basic architecture, the physical dimensions of the radiating element are replaced by the dimensions equivalent values obtained. Corresponds to an effective dielectric medium which replaces the existed permittivity of the material. The effective permittivity is different for CPW structures [8], [9], [10] when compared to the microstrip line configuration. It can be expressed as

$$
\begin{aligned}
\epsilon_{r e}=\frac{\epsilon_{r}+1}{2} & \left\{\tanh \left[0.775 \ln \left(\frac{h}{G}\right)+1.75\right]\right. \\
& \left.+\frac{k G}{h}\left[0.04-0.7 k+0.01\left(1-0.1 \epsilon_{r}\right)(0.25+k)\right]\right\}
\end{aligned}
$$

Where $\mathrm{W}=$ width of the centre conductor, $\mathrm{h}=$ thickness of substrate, $\mathrm{G}=$ the gap between the signal conductor and ground and $\mathrm{K}=\mathrm{W} /(\mathrm{W}+2 \mathrm{G})$

CPW line has the characteristic impedance which can be expressed in terms of elliptic function of the $1^{\text {st }}$ kind $K(k)$ as

$$
Z_{0_{C P W}}=\frac{20 \pi}{\sqrt{\epsilon_{r e}}} \frac{K^{\prime}(k)}{K(k)}
$$

Where $K^{\prime}=\sqrt{1}-K^{2}$ and $K^{\prime}(K)=K\left(K^{\prime}\right)$

The ratio of $K^{\prime}(k)$ and $K(k)$ is expressed by

$$
\begin{aligned}
\frac{K^{\prime}(k)}{K(k)} & =\left[\frac{\pi}{\ln \left(2 \frac{1+\sqrt{k^{\prime}}}{1-\sqrt{k^{\prime}}}\right)} \quad \text { if } 0<k<0.707\right. \\
= & {\left[\frac{1}{\pi} \ln \left(2 \frac{1+\sqrt{k^{\prime}}}{1-\sqrt{k^{\prime}}}\right)\right] \quad \text { if } 0.707<k<1 }
\end{aligned}
$$

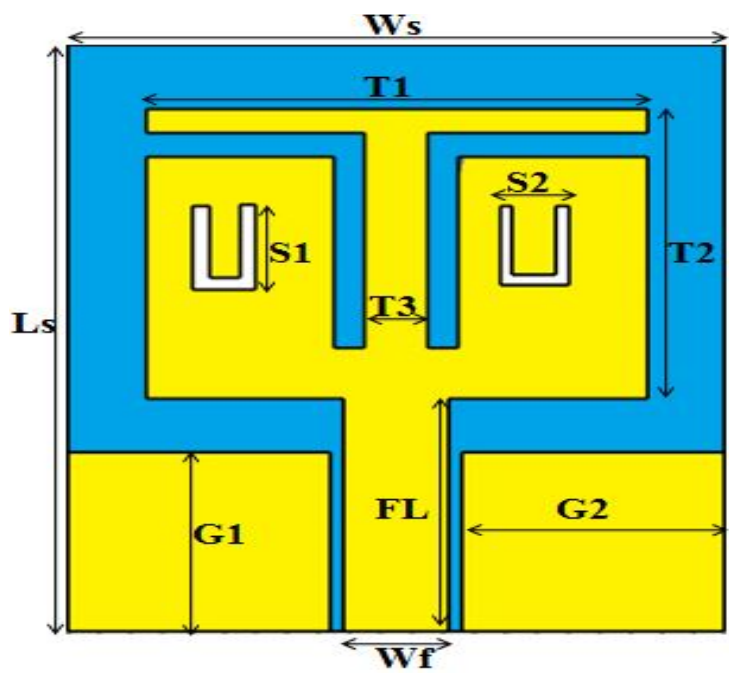

Figure 1: Dimensions of Basic model of a CPW Fed T-Stub \& U-Slot Notch band Antenna 
Table 1: Dimensions of Basic Antenna

\begin{tabular}{|c|c|c|c|c|}
\hline S.No & Parameter & Dimension in $\mathrm{mm}$ & Parameter & Dimension in $\mathrm{mm}$ \\
\hline 1 & Ws & 21 & T2 & 11.9 \\
\hline 2 & Ls & 24 & T3 & 2 \\
\hline 3 & Wf & 3.4 & G1 & 7.3 \\
\hline 4 & FL & 9.5 & G2 & 8.4 \\
\hline 5 & T1 & 16 & S1/S2 & $3 / 2$ \\
\hline
\end{tabular}

\section{RESULTS AND ANALYSIS}

The parametric analysis of the proposed antenna is accounted with respect to the patch, feed and ground plane. Fig. 2 shows that the parametric analysis of the feed width of the antenna Wf is varied from 3.2 to $3.8 \mathrm{~mm}$ and the simulated results for the change in $\mathrm{Wf}$ are shown in table 2. It is fixed at $3.2 \mathrm{~mm}$ since the fundamental resonant frequency is at $3 \mathrm{GHz}$ and second resonating band is from 5 to $8.8 \mathrm{GHz}$. When the value changed to $3.4 \mathrm{~mm}$, the fundamental resonant frequency is shifted back to $2.9 \mathrm{GHz}$ and second band is from 6 to $8 \mathrm{GHz}$. This second band is not covering any services. When the value changed to $3.6 \mathrm{~mm}$, the fundamental resonant frequency is at $3.8 \mathrm{GHz}$ and second band from 5.3 to $9.5 \mathrm{GHz}$. Fig.3 represents the reflection coefficient for change in the width of the T-stub T3 is varied from 2 to $3 \mathrm{~mm}$ and the simulated results for the change in $\mathrm{T}_{3}$ are shown in table 3 . The optimum dimension is fixed at $2 \mathrm{~mm}$ because fundamental resonant frequency is at $3 \mathrm{GHz}$ and second resonating band is from 5 to 8.8 GHz. Fig.4 shows the length of the U-slot antenna S1 is $3 \mathrm{~mm}$, and the simulated results for the change in $\mathrm{S}_{1}$ are shown in table 4. The designed antenna is showing optimum performance since the resonant frequency is at $3 \mathrm{GHz}$ and second resonating band is from 5 to $8.8 \mathrm{GHz}$.

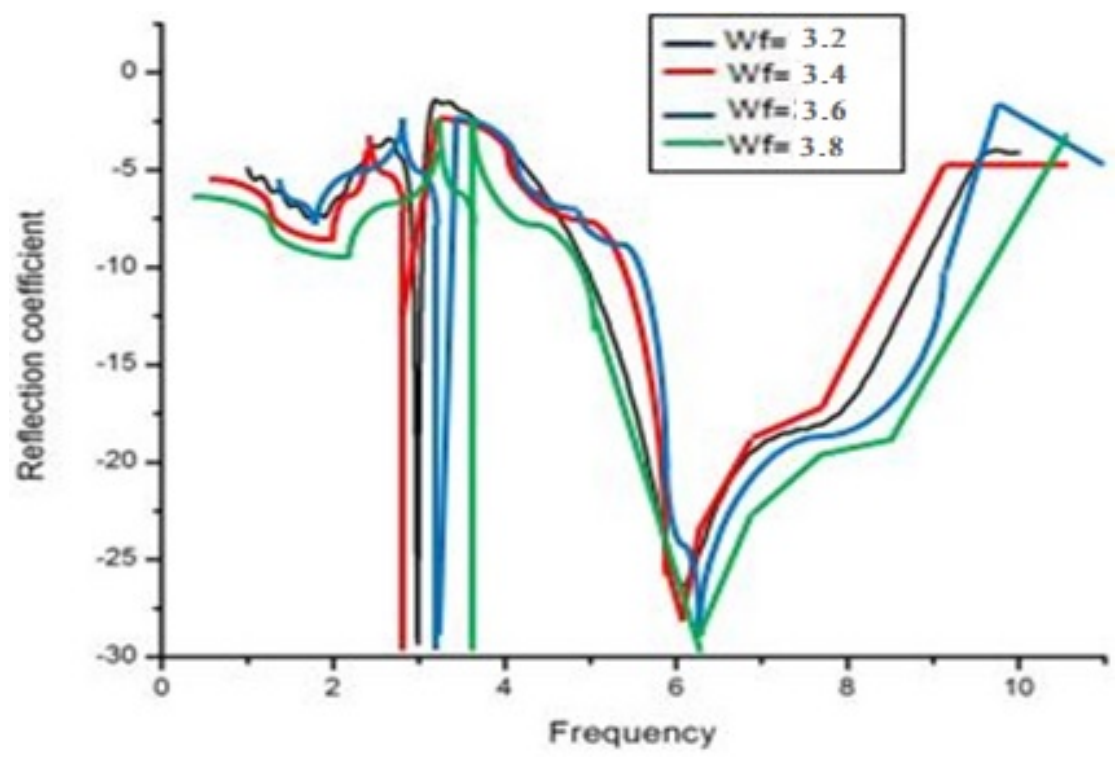

Figure 2: Reflection coefficient for change in Wf

Table 2: Simulated results for change in wf the Proposed Antenna

\begin{tabular}{|c|c|c|c|c|}
\hline $\begin{array}{c}\text { Width of the Feed (Wf) } \\
(\mathrm{mm})\end{array}$ & $\begin{array}{c}\text { Fundamental Resonating } \\
\text { frequency (GHz) }\end{array}$ & $\begin{array}{c}\text { Second } \\
\text { Resonating } \\
\text { Band } \\
(\mathrm{GHz})\end{array}$ & $\begin{array}{c}\text { Bandwidth } \\
(\mathrm{GHz})\end{array}$ & $\begin{array}{c}\text { Notch band } \\
(\mathrm{GHz})\end{array}$ \\
\hline 3.2 & 2.9 & $6-8$ & 2 & $\begin{array}{c}2.54(2.96- \\
5.5)\end{array}$ \\
\hline 3.4 & 3 & $5-8.8$ & 3.8 & $\begin{array}{c}1.99(3.01- \\
5)\end{array}$ \\
\hline
\end{tabular}


Design and Analysis of T-Stub U-Slot Notch Band Frequency Reconfigurable Antenna Using Parametric Analysis for Wireless Communication Applications

\begin{tabular}{|c|c|c|c|c|}
\hline 3.6 & 3.8 & $5.3-9.5$ & 4.2 & $1.95(3.35-$ \\
$5.3)$ \\
\hline 3.8 & 3.6 & $4.9-9.8$ & 4.9 & $1.2(3.7-$ \\
$4.9)$
\end{tabular}

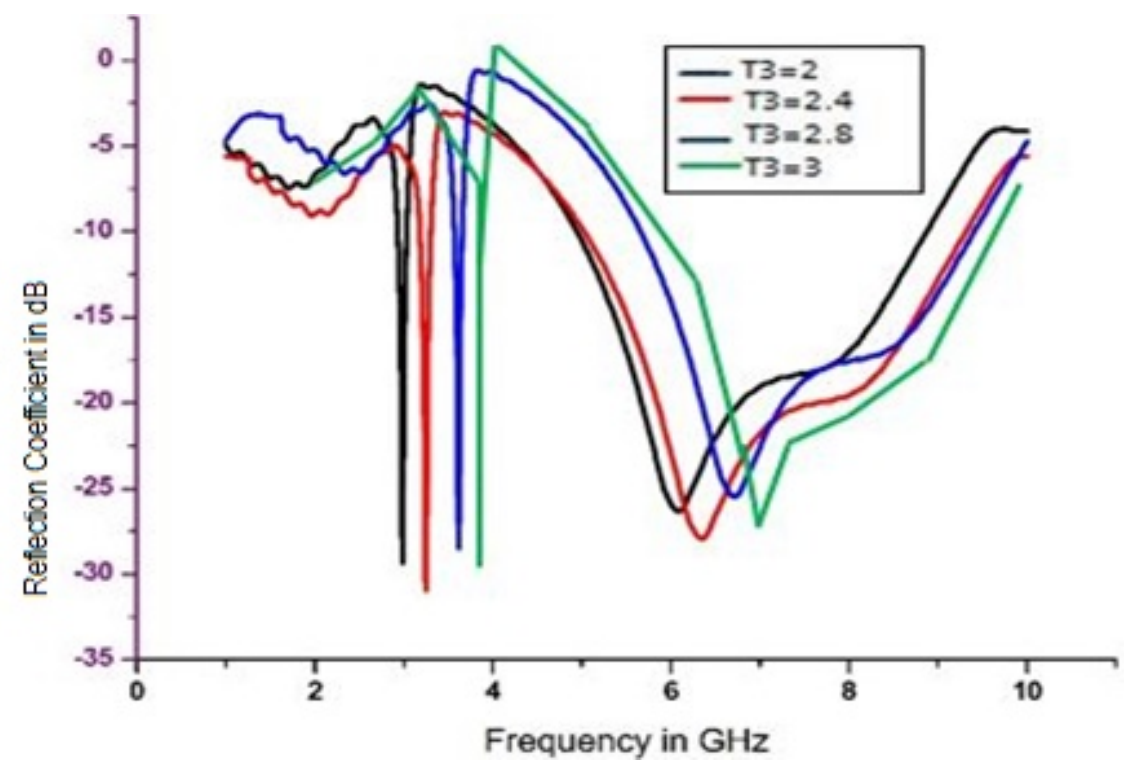

Figure 3: Reflection coefficient for change in T3

Table 3: Simulated results for change in T3 of the Proposed Antenna

\begin{tabular}{|c|c|c|c|c|}
\hline $\begin{array}{c}\text { Width of the T- } \\
\text { stub } \\
\text { T3 (mm) }\end{array}$ & $\begin{array}{c}\text { Fundamental Resonating frequency } \\
(\mathrm{GHz})\end{array}$ & $\begin{array}{c}\text { Second } \\
\text { Resonating } \\
\text { Band } \\
(\mathrm{GHz})\end{array}$ & $\begin{array}{c}\text { Bandwidth } \\
(\mathrm{GHz})\end{array}$ & $\begin{array}{c}\text { Notch band } \\
(\mathrm{GHz})\end{array}$ \\
\hline 2 & 3 & $5-8.8$ & 3.8 & $1.9(3.1-5)$ \\
\hline 2.4 & 3.45 & $5.1-9.2$ & 4.1 & $\begin{array}{c}1.64(3.46- \\
5.1)\end{array}$ \\
\hline 2.8 & 3.65 & $5.7-9.3$ & 3.6 & $2(3.7-5.7)$ \\
\hline 3 & 3.8 & $5.9-9.6$ & 3.7 & $1.6(4.3-5.9)$ \\
\hline
\end{tabular}

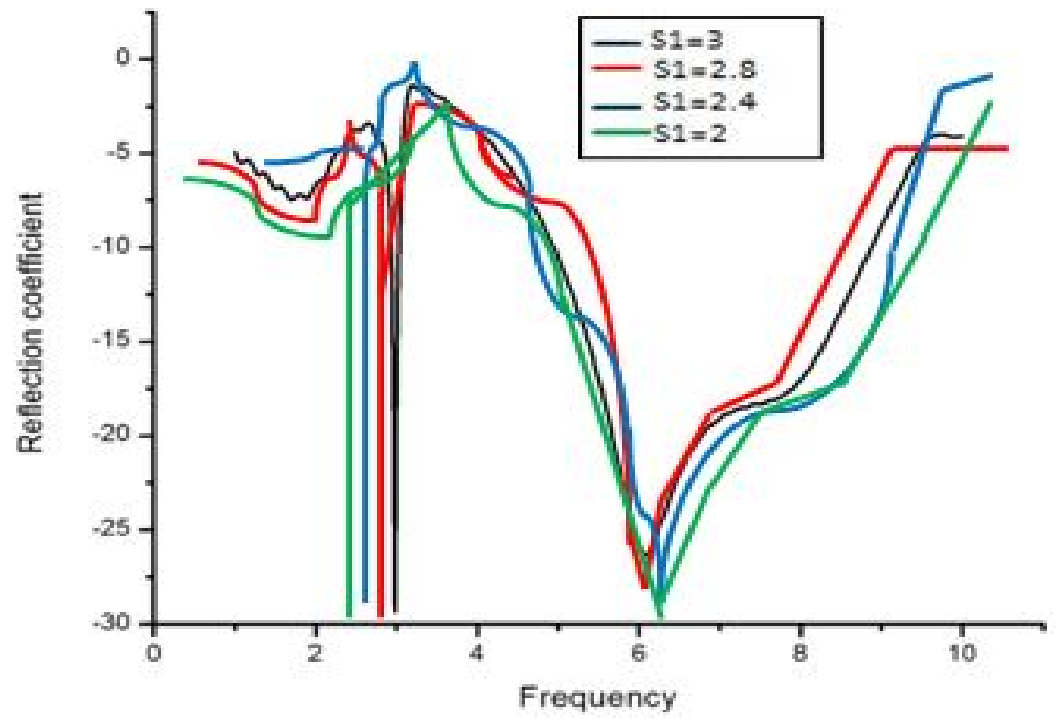

Figure 4: Reflection coefficient for change in S1 
Table 4: Simulated results for change in S1 of the Proposed Antenna

\begin{tabular}{|c|c|c|c|c|}
\hline $\begin{array}{l}\text { Length of the u-slot } \\
\text { (S1) (mm) }\end{array}$ & $\begin{array}{l}\text { Fundamental Resonating } \\
\text { frequency }(\mathrm{GHz})\end{array}$ & $\begin{array}{c}\text { Second } \\
\text { Resonating } \\
\text { Band } \\
(\mathrm{GHz})\end{array}$ & $\begin{array}{l}\text { Bandwidth } \\
\text { (GHz) }\end{array}$ & $\begin{array}{l}\text { Notch band } \\
\quad(\mathrm{GHz})\end{array}$ \\
\hline 3 & 3 & $5-8.8$ & 3.8 & $1.9(3.1-5)$ \\
\hline 2.8 & 2.75 & $5.4-8.5$ & 3.1 & $\begin{array}{c}2.55(2.85- \\
5.4)\end{array}$ \\
\hline 2.4 & 2.5 & $4.7-9.1$ & 4.4 & $\begin{array}{c}2.2(2.5- \\
4.7)\end{array}$ \\
\hline 2 & 2.4 & $4.6-9.6$ & 4.7 & $\begin{array}{c}2.2(2.4- \\
4.6)\end{array}$ \\
\hline
\end{tabular}

\section{CONCLUSION}

A compact T-Stub U-Slot frequency reconfigurable antenna with notch band for WLAN, Wi-Fi, LTE and Bluetooth applications is presented in this paper. Parametric analysis is done on the width of the feed $\left(\mathrm{W}_{\mathrm{f}}\right)$, width of the T-stub (T3) and length of the U-slot (S1) to get the optimised performance characteristics of the designed antenna. From the results, it is clearly showing that, Wf is fixed at $3.2 \mathrm{~mm}, \mathrm{~T} 3$ is showing better results at $3 \mathrm{~mm}$ and S1 is giving optimum results at $3 \mathrm{~mm}$. The designed T-Stub U-Slot notch band frequency reconfigurable antenna is operating in the dual band with narrow bandwidth at fundamental resonant frequency and wide bandwidth at second resonant frequency which covers almost all the applications in the Ultra-Wide band range.

\section{SOURCES OF FUNDING}

None.

\section{CONFLICT OF INTEREST}

None.

\section{ACKNOWLEDGMENT}

None.

\section{REFERENCES}

[1] Cho, Y.J., Hwang, S.H., and Park, S.O, "Printed antenna with folded nonuniform meander line for 2.4/5 GHz WLAN bands", Electronics Letters, Vol 41, Issue 14, 2005, pp. 786-788.

[2] G. Vaishnavi, V. Manichandana, Ch Harinath Reddy, S. Ravi Teja, J. Sesi Kumar, “Compact Sierpinski Carpet Antenna on Destructive Ground Plane", International Journal of Applied Engineering Research, ISSN 09734562, Volume 8, Number 4, June-2013, pp. 343-352.

[3] S. S. Mohan Reddy, Bandi Sanjay, D.Ujwala, Trident Shaped Ultra-Wideband Antenna Analysis based on Substrate Permittivity, International Journal of Applied Engineering Research, ISSN 0973-4562, Volume 8, Number 12, Nov-2013, pp. 1355-1361.

[4] Suraj Chhatkuli, A. Manikanta prasanth, Y. Bhargav, U. Dinesh Naga Venkata Sai, Syed Feeraz, Measurement of Dimensional Characteristics of Microstrip Antenna based on Mathematical Formulation, International Journal of Applied Engineering Research, ISSN 0973-4562, Volume 9, Number 9, March-2014, pp. 1063-1074.

[5] B. Sadasivarao, "Analysis of Hybrid Slot Antenna based on Substrate Permittivity", ARPN Journal of Engineering and Applied Sciences, Vol. 9, No. 6, June-2014, pp 885-890. 
[6] M L S N S Lakshmi, Habibulla Khan, "Novel Sequential Rotated 2x2 Array Notched Circular Patch Antenna", Journal of Engineering Science and Technology Review, Vol 8, issue 4, Dec-2015, pp 73-77.

[7] Kosuru Murthy, Kodidasu Umakantham, Korlapati Satyanarayana Murthy, "Reconfigurable Notch Band Monopole Slot Antenna for WLAN/IEEE-802.11n Applications", International Journal of Intelligent Engineering and Systems, Vol 10, No 6, Oct-2017, pp 166-173.

[8] Sri Jayalakshmi, Habibulla Khan, A CPW Monopole Antenna with Dual Band Characteristics for WLAN and WiMAX Applications, Journal of Advanced Research in Dynamical and Control Systems, Vol 9, No 18, 2017, pp 52-60.

[9] Sri Jayalakshmi, A CPW Fed U-Shaped Slot Antenna Array for WLAN and Air Surveillance Radar Applications, International Journal of Pure and Applied Mathematics, Volume 117, No. 18, 2017, pp 67-73.

[10] T. Anusha, T. V. Ramakrishna, A. N. Meena Kumari, "Dual-Band-Notched CPW-Fed Antennas with WiMAX/WLAN Rejection for UWB Communication", Lecture Notes in Electrical Engineering, ISSN: 18761100, Vol 471, 2018, pp 559-570. 